Supplementary Information

\title{
Deciphering single-bacterium adhesion behavior modulated by extracellular electron transfer
}

Shuomeng Zhang1, 2, 8, Lei Wang1,8, Liang $\mathrm{Wu}^{3,8}$, Zhongjian $\mathrm{Li}^{1,4,5^{*}}$, Bin Yang ${ }^{1,4}$, Yang Hou,

4, 5, Lecheng Lei ${ }^{1,4,5}$, Shaoan Cheng ${ }^{6}$, Qinggang $\mathrm{He}^{1,2,7^{*}}$

${ }^{1}$ College of Chemical and Biological Engineering, Zhejiang University, Hangzhou, Zhejiang 310027, China

2 Zhejiang Provincial Key Laboratory of Advanced Chemical Engineering Manufacture Technology, Zhejiang University, Hangzhou, Zhejiang 310027, China

3 School of Chemistry and Chemical Engineering, Shanghai Jiao Tong University, 800 Dong

Chuan Rd., Shanghai 200240, China

${ }^{4}$ Institute of Zhejiang University - Quzhou, Quzhou 32400, China

5 Key Laboratory of Biomass Chemical Engineering of Ministry of Education, Zhejiang University, Hangzhou 310027, China

${ }^{6}$ College of Energy Engineering, Zhejiang University, Hangzhou, Zhejiang 310027, China

${ }^{7}$ Ningbo Research Institute, Zhejiang University, Ningbo, Zhejiang 315100, China

8 These authors contributed equally to this work.

E-mail: zdlizj@zju.edu.cn (Z. Li); qghe@zju.edu.cn (Q. He) 
The supplementary information includes:

Supplementary Note 1-10

Supplementary Table 1-3

Supplementary Figure 1-10

References 


\section{Supplementary note 1: Construction of the in situ ESCFS measurement system and the calibration of the reference electrode}

We integrated a three-electrode electrochemical cell and an IOM into AFM to construct the in situ ESCFS measurement system, as shown in Figure 1a. The three-electrode electrochemical cell was fabricated as follows. A piece of transparent anodic bonded glass plate $\left(45 * 45 \mathrm{~mm}^{2}\right.$, thickness $0.5 \mathrm{~mm}$, Borofloat 33, Germany Schott) was utilized as the substrate of the electrochemical cell (Figure S1). Two interdigitated gold film electrodes with a thickness of 300 $\mathrm{nm}$ were deposited on the upper surface of the glass plate via vacuum vapor deposition, where a $50 \mathrm{~nm}$ Ti buffer layer was deposited on the anodic bonded glass plate by thermal evaporation first, followed by a $300 \mathrm{~nm}$ gold layer, with an evaporation rate of $1 \AA$ /s by a high vacuum resistance evaporation coating instrument (VZZ-300S, VNANO, China). These two interdigitated gold film electrodes served as the working electrode (WE) and counter electrode (CE) (Figure 1b). A Ag wire (diameter: $0.5 \mathrm{~mm}$ ) with a $\mathrm{AgCl}$ coating served as the reference electrode (RE). A polytetrafluoroethylene (PTFE) cell was fixed on the sample table by four screws, and an $\sim 3.2 \mathrm{~mL}$ electrochemical cell was thus completed. The potential of the $\mathrm{Ag} / \mathrm{AgCl}$ wire was calibrated relative to that of $\mathrm{Ag} / \mathrm{AgCl}$ (saturated $\mathrm{KCl}$ ) by cyclic voltammetry in $5 \mathrm{mM}$ $\mathrm{K}_{3}\left[\mathrm{Fe}(\mathrm{CN})_{6}\right]$ in the presence of $0.1 \mathrm{M} \mathrm{KCl}$. Figure S2 illustrates that the potential of the RE was $0.077 \mathrm{~V}$ vs. $\mathrm{Ag} / \mathrm{AgCl}$ (saturated $\mathrm{KCl}$ ). All potentials mentioned are relative to $\mathrm{Ag} / \mathrm{AgCl}$ (saturated $\mathrm{KCl}$ ), unless otherwise specified. 


\section{Supplementary note 2: Bacterial strain and growth conditions}

S. oneidensis MR-1 was used in this study and was preserved at $-80^{\circ} \mathrm{C}$. Before use, it was transferred to a $-20^{\circ} \mathrm{C}$ refrigerator for $2 \mathrm{~h}$ and then transferred to a $0{ }^{\circ} \mathrm{C}$ refrigerator for $2 \mathrm{~h}$. The bacterial suspension was prepared by transferring $400 \mu \mathrm{L}$ of bacterial solution with a sterilized pipette to a $50 \mathrm{~mL}$ centrifuge tube containing $20 \mathrm{~mL}$ of LB broth (Miller, Sigma-Aldrich). Then, the bacterial suspension was incubated at $30{ }^{\circ} \mathrm{C}$ with $200 \mathrm{rpm}$ shaking for $24 \mathrm{~h}$ until mid-exponential growth phase $\left(\mathrm{OD}_{600 \mathrm{~nm}} \approx 1.0-1.2\right)$. Next, $400 \mu \mathrm{L}$ of the suspension was inoculated into a $50 \mathrm{~mL}$ centrifuge tube containing $20 \mathrm{~mL}$ of $\mathrm{M} 9$, followed by incubation at $30{ }^{\circ} \mathrm{C}$ and $200 \mathrm{rpm}$ for $24 \mathrm{~h}\left(\mathrm{OD}_{600 \mathrm{~nm}} \approx 0.6-0.8\right)$. Then, it was centrifuged at $5000 \mathrm{rpm}$ for $5 \mathrm{~min}$ and suspended in PBS (pH 7.2-7.4, Biosharp), and this process was repeated three times. All of the reagents and materials used in this process were autoclaved at $121^{\circ} \mathrm{C}$ for 20 min (ZEALWAY, DR85DF) before use. Details of the preparation of M9 nutrient solution are shown in supplementary note 3-4. 


\section{Supplementary note 3: Preparation of M9 nutrient solution.}

The composition of the M9 nutrient solution used in this work is shown in Table S1.

Table S1. Composition of the M9 nutrient solution

\begin{tabular}{cc}
\hline Component & Content \\
\hline Disodium hydrogen phosphate dodecahydrate $\left(\mathrm{Na}_{2} \mathrm{HPO}_{4} \cdot 12 \mathrm{H}_{2} \mathrm{O}\right)$ & $15.036 \mathrm{~g} / \mathrm{L}$ \\
Sodium chloride $(\mathrm{NaCl})$ & $3 \mathrm{~g} / \mathrm{L}$ \\
Ammonium chloride $\left(\mathrm{NH}_{4} \mathrm{Cl}\right)$ & $0.5 \mathrm{~g} / \mathrm{L}$ \\
Magnesium sulfate heptahydrate $\left(\mathrm{MgSO}{ }_{4} \cdot 7 \mathrm{H}_{2} \mathrm{O}\right)$ & $1 \mathrm{~g} / \mathrm{L}$ \\
$100 x$ CaCl ${ }_{2}$ Stock Solution & $0.246 \mathrm{~g} / \mathrm{L}$ \\
Minerals Solution & $2.06 \mathrm{~mL} / \mathrm{L}$ \\
Vitamin Solution & $12.5 \mathrm{~mL} / \mathrm{L}$ \\
Sodium L-lactate $\left(\mathrm{C}_{3} \mathrm{H}_{5} \mathrm{P}_{3} \mathrm{Na}_{4}\right)$ & $12.5 \mathrm{~mL} / \mathrm{L}$ \\
\hline
\end{tabular}

Since vitamin solution and sodium L-lactate cannot be sterilized by autoclaving, the vitamin solution and sodium L-lactate were first filtered through $0.22 \mu \mathrm{m}$ filters and then placed in a UV sterilizer. The solution without the addition of vitamin solution and sodium L-lactate was sterilized at $121{ }^{\circ} \mathrm{C}$ for 20 min. Finally, the vitamin solution and sodium L-lactate filtered by $0.22 \mu \mathrm{m}$ filters were added to the solution in the sterilization cabinet. Then the solution was marked and placed in the sterilization cabinet. 


\section{Supplementary note 4: Preparation of the mineral and vitamin solutions.}

The composition of the mineral solution in Table S1 is shown in Table S2.

\section{Table S2. Composition of the mineral solution}

\begin{tabular}{|c|c|}
\hline Component & Content \\
\hline Nitrilotriacetic acid $\left(\mathrm{N}\left(\mathrm{CH}_{2} \mathrm{COOH}\right)_{3}\right)$ & $1.5 \mathrm{~g} / \mathrm{L}$ \\
\hline Magnesium sulphate $\left(\mathrm{MgSO}_{4}\right)$ & $3 \mathrm{~g} / \mathrm{L}$ \\
\hline Manganese sulfate monohydrate $\left(\mathrm{MnSO}_{4} \cdot \mathrm{H}_{2} \mathrm{O}\right)$ & $0.5 \mathrm{~g} / \mathrm{L}$ \\
\hline Sodium chloride $(\mathrm{NaCl})$ & $1 \mathrm{~g} / \mathrm{L}$ \\
\hline Ferrous sulfate heptahydrate $\left(\mathrm{FeSO}_{4} \cdot 7 \mathrm{H}_{2} \mathrm{O}\right)$ & $0.1 \mathrm{~g} / \mathrm{L}$ \\
\hline Calcium chloride dihydrate $\left(\mathrm{CaCl}_{2} \cdot 2 \mathrm{H}_{2} \mathrm{O}\right)$ & $0.1 \mathrm{~g} / \mathrm{L}$ \\
\hline Cobalt chloride hexahydrate $\left(\mathrm{CoCl}_{2} \cdot 6 \mathrm{H}_{2} \mathrm{O}\right)$ & $0.1 \mathrm{~g} / \mathrm{L}$ \\
\hline Zinc chloride $\left(\mathrm{ZnCl}_{2}\right)$ & $0.13 \mathrm{~g} / \mathrm{L}$ \\
\hline Copper sulfate pentahydrate $\left(\mathrm{CuSO}_{4} \cdot 5 \mathrm{H}_{2} \mathrm{O}\right)$ & $0.01 \mathrm{~g} / \mathrm{L}$ \\
\hline \multicolumn{2}{|l|}{ Aluminum potassium sulfate dodecahydrate } \\
\hline & $0.01 \mathrm{~g} / \mathrm{L}$ \\
\hline \multicolumn{2}{|l|}{$\left(\mathrm{AlK}\left(\mathrm{SO}_{4}\right)_{2} \cdot 12 \mathrm{H}_{2} \mathrm{O}\right)$} \\
\hline Boric acid $\left(\mathrm{H}_{3} \mathrm{BO}_{3}\right)$ & $0.01 \mathrm{~g} / \mathrm{L}$ \\
\hline Sodium molybdate Nickel chloride hexahydrate $\left(\mathrm{NaMoO}_{4}\right)$ & $0.025 \mathrm{~g} / \mathrm{L}$ \\
\hline Nickel chloride hexahydrate $\left(\mathrm{NiCl}_{2} \cdot 6 \mathrm{H}_{2} \mathrm{O}\right)$ & $0.024 \mathrm{~g} / \mathrm{L}$ \\
\hline Sodium tungstate dihydrate $\left(\mathrm{NaWO}_{4} \cdot 2 \mathrm{H}_{2} \mathrm{O}\right)$ & $0.025 \mathrm{~g} / \mathrm{L}$ \\
\hline
\end{tabular}


The composition of the vitamin solution in Table S1 is shown in Table S3.

Table S3. Composition of the vitamin solution

\begin{tabular}{cc}
\hline Component & Content \\
\hline Biotin $\left(\mathrm{C}_{10} \mathrm{H}_{16} \mathrm{~N}_{2} \mathrm{O}_{3} \mathrm{~S}\right)$ & $2 \mathrm{mg} / \mathrm{L}$ \\
Pyridoxine hydrochloride $\left(\mathrm{C}_{8} \mathrm{H}_{11} \mathrm{NO}_{3} \cdot \mathrm{HCl}\right)$ & $10 \mathrm{mg} / \mathrm{L}$ \\
Riboflavin $\left(\mathrm{C}_{17} \mathrm{H}_{20} \mathrm{~N}_{4} \mathrm{O}_{6}\right)$ & $5 \mathrm{mg} / \mathrm{L}$ \\
Folic acid $\left(\mathrm{C}_{19} \mathrm{H}_{19} \mathrm{~N}_{7} \mathrm{O}_{6}\right)$ & $2 \mathrm{mg} / \mathrm{L}$ \\
Pantothenic acid $\left(\mathrm{C}_{9} \mathrm{H}_{17} \mathrm{NO}_{5}\right)$ & $5 \mathrm{mg} / \mathrm{L}$ \\
Thiamin $\left(\mathrm{C}_{12} \mathrm{H}_{17} \mathrm{ClN}_{4} \mathrm{OS}_{3} \cdot \mathrm{HCl}_{3}\right)$ & $5 \mathrm{mg} / \mathrm{L}$ \\
p-Aminobenzoic acid $\left(\mathrm{C}_{7} \mathrm{H}_{7} \mathrm{NO}_{2}\right)$ & $5 \mathrm{mg} / \mathrm{L}$ \\
Thioctic acid $\left(\mathrm{C}_{8} \mathrm{H}_{14} \mathrm{O}_{2} \mathrm{~S}_{2}\right)$ & $5 \mathrm{mg} / \mathrm{L}$ \\
Vitamin B12 $\left(\mathrm{C}_{63} \mathrm{H}_{88} \mathrm{CoN}_{14}\right)$ & $5 \mathrm{mg} / \mathrm{L}$ \\
\hline
\end{tabular}

The mineral and vitamin solutions do not need sterilization operation after preparation, and they should be marked and stored in the refrigerator at $4{ }^{\circ} \mathrm{C}$. 


\section{Supplementary note 5: Functionalization of the cantilever with a single $S$. oneidensis MR-1}

The anodic bonded glass plate deposited with gold film electrodes was ultrasonically cleaned in ultrapure water $(18.2 \mathrm{M} \Omega \cdot \mathrm{cm}$, Heal Force) for $15 \mathrm{~min}$ and dried under a continuous and steady $\mathrm{N}_{2}$ flow for $15 \mathrm{~min}$. Then the glass plate was $\mathrm{UV} / \mathrm{O}_{3}$-cleaned for $15 \mathrm{~min}$. Subsequently, a 10- $\mu \mathrm{L}$ droplet of the bacterial suspension was dropped directly on the glass plate between working electrode and counter electrode, and the droplet was allowed to stand for 30 min to allow S. oneidensis MR-1 to attach to the glass surface (Figure 1c) ${ }^{1}$. The concentration of the bacterial suspension needs to be diluted in order to ensure the $S$. oneidensis MR-1 attach to the glass surface separately. Then the glass plate was tilted 30 degrees and rinsed with $3 \mathrm{~mL}$ of PBS to remove the unattached bacteria and prevent the $S$. oneidensis MR-1 from contacting the working electrode. Subsequently, the as-prepared glass plate was mounted on the electrochemical cell and $2.5 \mathrm{~mL}$ of test solution was immediately added to the electrochemical cell.

Single $S$. oneidensis MR-1 was immobilized on the end of cantilever by using polydopamine (PDA) as the wet adhesive ${ }^{2}$. The PDA solution was prepared by dissolving dopamine hydrochloride powder (0.4 g, Sigma-Aldrich) to $100 \mathrm{~mL}$ of Trizma buffer (10 mM, BioReagent, Sigma-Aldrich), then the solution was buffered to $\mathrm{pH}=8.5$ with $1 \mathrm{M} \mathrm{NaOH}{ }^{2-3}$. Silicon nitride atomic force microscope (AFM) probes (nominal $k=0.06 \mathrm{~N} / \mathrm{m}$, Novascan Technologies, Ames, IA, USA) with a $\mathrm{SiO}_{2}$ micro-ball (diameter: $2.5 \mu \mathrm{m}$ ) on the head of triangle cantilever were used. To ensure the adhesiveness, the PDA solution and the probes with a PDA coating need to be prepared right before every experiment. The AFM probes were put into the $\mathrm{UV} / \mathrm{O}_{3}$-cleaner and cleaned for $10 \mathrm{~min}$, followed by being immersed into $10 \mathrm{~mL}$ of PDA solution. 
After shaking at $60 \mathrm{rpm}$ for $15 \mathrm{~min}$ on a biological shaker, the probes were rinsed with ultrapure water $\left(18.2 \mathrm{M} \Omega \bullet \mathrm{cm}\right.$, Heal Force) and dried under a continuous and steady $\mathrm{N}_{2}$ flow for 30 min.

Functionalization of the cantilever with a single $S$. oneidensis MR-1 was conducted at $25^{\circ} \mathrm{C}$ utilizing AFM (Agilent 5500, USA), which was integrated into an IOM (LEICA DMi1). An AFM probe with a PDA coating was mounted on the AFM scanner and the electrochemical cell was mounted on the AFM subsequently. The electrochemical cell was then elevated slowly by manual to make the probe immerse into the electrochemical cell, allowing the triangle cantilever deflection to reach a steady deflection value (typically observed within 60 min). After that, the electrochemical cell was elevated at a slow speed of $0.5 \mu \mathrm{m} / \mathrm{s}$. Then force-curves measurements were conducted over the bare glass plate using contact mode AFM at a cantilever speed of 0.2 $\mu \mathrm{m} / \mathrm{s}$. The deflection sensitivity of the cantilever was obtained from the slope of the contact region of deflection signal (V) vs piezo extension (nm) curves collected. Then the cantilever was withdrawn. With the help of a $60 \times$ objective of IOM, the electrochemical cell was moved horizontally and slowly in order to keep one single S. oneidensis MR-1 directly under the PDA-coated $\mathrm{SiO}_{2}$ micro-ball that was attached to the head of cantilever. Then the electrochemical cell was elevated at a slow speed of $0.5 \mu \mathrm{m} / \mathrm{s}$, allowing the single $S$. oneidensis MR-1 to approach the PDA-coated $\mathrm{SiO}_{2}$ micro-ball. The cantilever was engaged in contact mode over S. oneidensis MR-1 for 5 min with a $0.5 \mathrm{nN}$ loading force, after which the cantilever was withdrawn, and a single $S$. oneidensis MR-1 was functionalized on the $\mathrm{SiO}_{2}$ microball. 


\section{Supplementary note 6: Force measurements between a single $S$. oneidensis MR-1 and a gold film electrode.}

The electrochemical cell was moved horizontally and slowly to keep the gold film electrode directly under the as prepared cantilever that was functionalized with single S. oneidensis MR-1. This electrochemical cell was connected to a potentiostat (Autolab PGSTAT204) that was controlled by a computer through GPIB-to-USB cables through a software suite (Metrohm Autolab Nova 2.1). In this study, chronoamperometry (CA) was performed in order to hold gold film electrode at different electrode potentials. The force-curves measurements were performed at $25^{\circ} \mathrm{C}$ in an electrochemical cell that was filled with different test solutions under aerobic and anaerobic conditions. And these experiments were conducted using contact mode AFM at a cantilever speed of $0.2 \mu \mathrm{m} / \mathrm{s}$ and force distance of $1 \mu \mathrm{m}$. When the loading force of the cantilever reached a set value of $0.5 \mathrm{nN}$, the cantilever stopped and remained constant for $5 \mathrm{~s}$, and then the S. oneidensis MR-1 was pulled from the gold film electrode by the cantilever. These force-distance curves data were obtained at some randomly chosen positions on the gold film electrode surface. Notably, just three reproducible force curves would be collected over each position in order to avoid the deposition of extracellular polymeric substances. For each measurement condition, at least three individual bacteria (from three independent bacteria cultures) were utilized to obtain a total of 100 250 force-distance curves for statistical analyses.

Raw data (i.e., cantilever deflection signal (V) versus piezo Z position) were converted into force-distance curves by multiplying the cantilever deflection signal (V) with the spring constant $(\mathrm{N} / \mathrm{m})$ of cantilever and the deflection sensitivity $(\mathrm{nm} / \mathrm{V})$. The maximum adhesion force (FAd) 
between S. oneidensis MR-1 and gold film electrode was obtained from each force-distance curve. After each experiment, L7012 live/dead BacLight bacterial viability kits were used to check the viability of the $S$. oneidensis MR-1 that was immobilized on the cantilever. $7.5 \mu \mathrm{L}$ of component A and $7.5 \mu \mathrm{L}$ of component B of kits L7012 were mixed thoroughly in a microfuge tube. $15 \mu \mathrm{L}$ of the dye mixture was added to $5 \mathrm{~mL}$ of the PBS and mixed thoroughly, then the probe functionalized with $S$. oneidensis MR-1 on cantilever was dismounted from the scanner and immersed into the dye solution immediately, which was incubated at room temperature in the dark for 15 min. After that, the probe was observed in a fluorescence microscope (Nikon ECLIPSE E200, Japan). Live bacteria stained fluorescent green, whereas dead bacteria stained fluorescent red. 


\section{Supplementary note 7: Biofilm formation on a gold electrode.}

Biofilm formation on a gold electrode was performed in a three-electrode reactor. A $10 \times 20$ $\mathrm{mm}^{2}$ gold electrode served as the WE, a $10 \times 10 \mathrm{~mm}$ Pt mesh served as the $\mathrm{CE}$ and $\mathrm{Ag} / \mathrm{AgCl}$ (saturated $\mathrm{KCl}$ ) served as the RE. All components of this three-electrode system, including the reactor, WE, CE, RE and magnetons, were thoroughly cleaned and autoclave sterilized for 20 $\min$ at $121^{\circ} \mathrm{C}$. After cooling, they were put into a UV sterilizer for use. S. oneidensis MR-1 in the mid-exponential growth phase $\left(\mathrm{OD}_{600 \mathrm{~nm}} \approx 1.0-1.2\right)$ in $20 \mathrm{~mL}$ of LB broth was centrifuged at $5000 \mathrm{rpm}$ for $5 \mathrm{~min}$ and then suspended in M9, and this process was repeated three times to remove the LB residue. Finally, S. oneidensis MR-1 was suspended in $75 \mathrm{~mL}$ of M9 (OD600 $\mathrm{mm}$ $\approx 0.8$ ) and added to the reactor. Biofilm formation experiments were performed under the conditions of different electrode potentials and solution compositions with 200 rpm magnetic stirring for $24 \mathrm{~h}$ at $25^{\circ} \mathrm{C}$. After each experiment, L7012 live/dead BacLight bacterial viability kits were used to check the viability of the $S$. oneidensis MR-1 biofilm. Component A (4.5 $\mu \mathrm{L})$ and component B $(4.5 \mu \mathrm{L})$ from the $\mathrm{L} 7012$ kits were mixed thoroughly in a microfuge tube. $9 \mu \mathrm{L}$ of the dye mixture was added to $3 \mathrm{~mL}$ of PBS and mixed thoroughly. Then, the WE was dismounted from the three-electrode reactor and gently rinsed with PBS to remove the unattached bacteria and immersed into the dye solution immediately and incubated at room temperature in the dark for $15 \mathrm{~min}$. Then, the WE was covered by an $18 \mathrm{~mm}$ square coverslip and observed under a fluorescence microscope (Nikon, DS-Qi2) to obtain fluorescence images of the biofilm. 


\section{Supplementary note 8: Calculation of the bacterial density of the biofilm formed on the}

\section{gold electrode.}

The bacterial density of the biofilm formed on the gold electrode was estimated from the fluorescence images by using Adobe Photoshop. First, we selected a representative fluorescence image of the biofilm formed on the gold electrode. Second, the magic wand tool in continuous mode with a tolerance value of 32 was used to determine the pixel number $\left(\mathrm{N}_{\mathrm{s}}\right)$ of every $S$. oneidensis MR-1 cell. Furthermore, pixel number histograms of a single S. oneidensis MR-1 cell in the fluorescence image were obtained. The average pixel number of every S. oneidensis MR-1 cell was 60.6. Then, the magic wand tool in noncontinuous mode with a tolerance value of 32 was used to determine the total pixel number $\left(\mathrm{N}_{\mathrm{T}}\right)$ of the green area throughout the fluorescence image of the biofilm formed on the gold film electrode under various conditions. Finally, the

number $\left(\mathrm{N}_{\mathrm{c}}\right)$ of $\mathrm{S}$. oneidensis $\mathrm{MR}-1$ cells in every fluorescence image was obtained by calculating the quotient of $\mathrm{N}_{\mathrm{T}}$ and $\mathrm{N}_{\mathrm{s}}\left(\mathrm{N}_{\mathrm{T}} / \mathrm{N}_{\mathrm{s}}\right)$, and then the bacterial density was estimated by calculating the quotient of $\mathrm{N}_{c}$ and the image area $\mathrm{S}\left(\mathrm{N}_{\mathrm{c}} \mathrm{S}, \mathrm{S}=3.6 \times 10^{-3} \mathrm{~cm}^{2}\right)$. The average bacterial density of the biofilm formed on the gold film electrode under various conditions was calculated from five randomly selected $600 \times 600 \mu \mathrm{m}^{2}$ scanning areas under various conditions. 


\section{Supplementary note 9: Numerical WLC modelling.}

To elucidate the underlying mechanism of the unfolding behaviour of extracellular proteins, the force-distance curves measured by ESCFS are modelled using a WLC model. Eq. (5) was fitted to the region of unfolding events in the force-distance curves, which show saw-toothed unfolding peaks. 


\section{Supplementary note 10: Data and statistical analysis}

Statistical significance was calculated using a two-tailed unpaired t-test when more than two groups were compared. $P$ values and statistical parameters are indicated in the figures and figure

legends, respectively. The error bars represent the standard deviation throughout. For all experiments, the statistical significance level $\alpha$ was set to $<0.05$. 


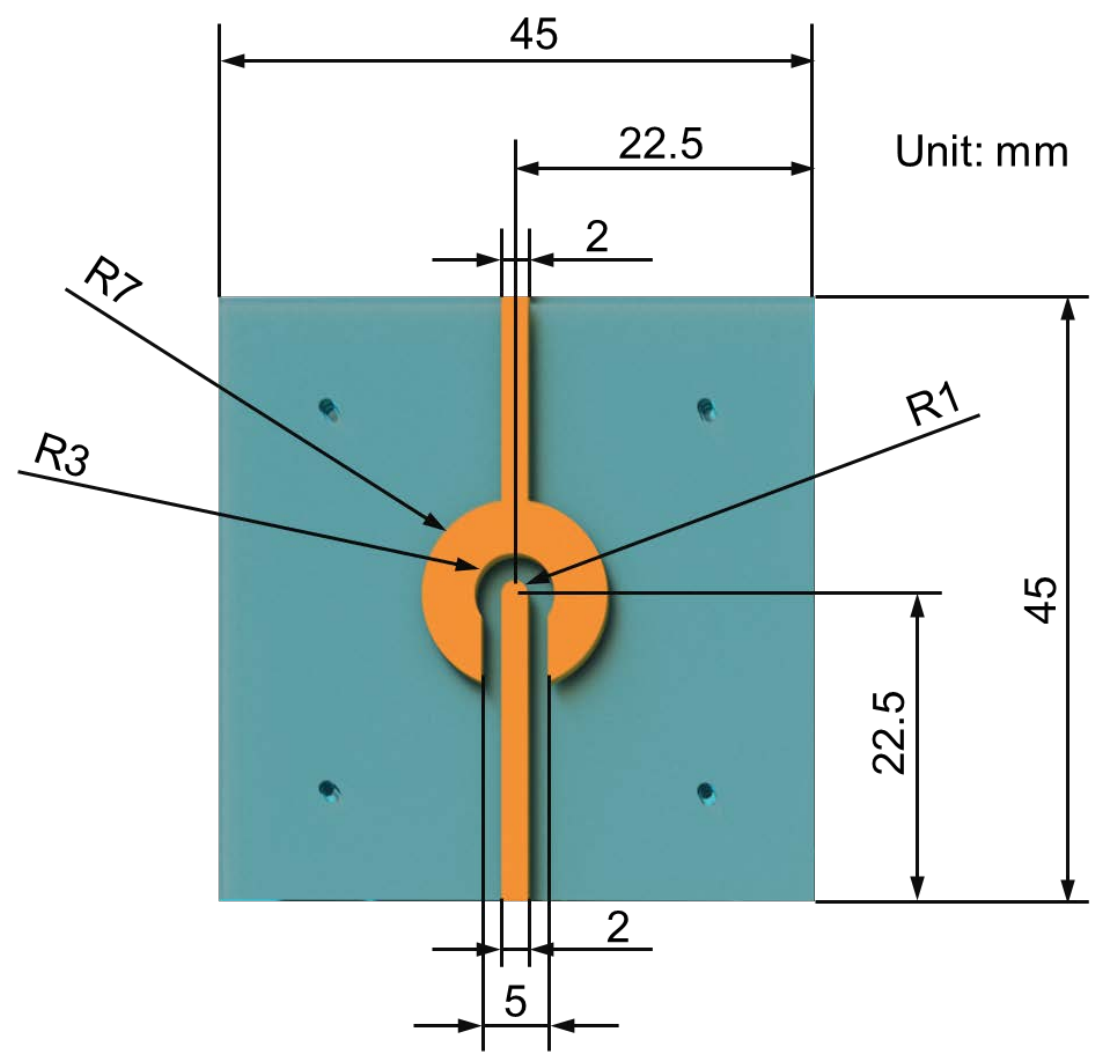

Figure S1. Geometric size of the transparent anodic bonded glass plate $\left(45^{*} 45 \mathrm{~mm}^{2}\right.$, thickness 0.5mm, Borofloat 33, Germany Schott) that was utilized as the substrate of the electrochemical cell in this study $\left(\mathrm{R}_{\mathrm{x}}\right.$ : radius $\left.=\mathrm{x} \mathrm{mm}\right)$. 


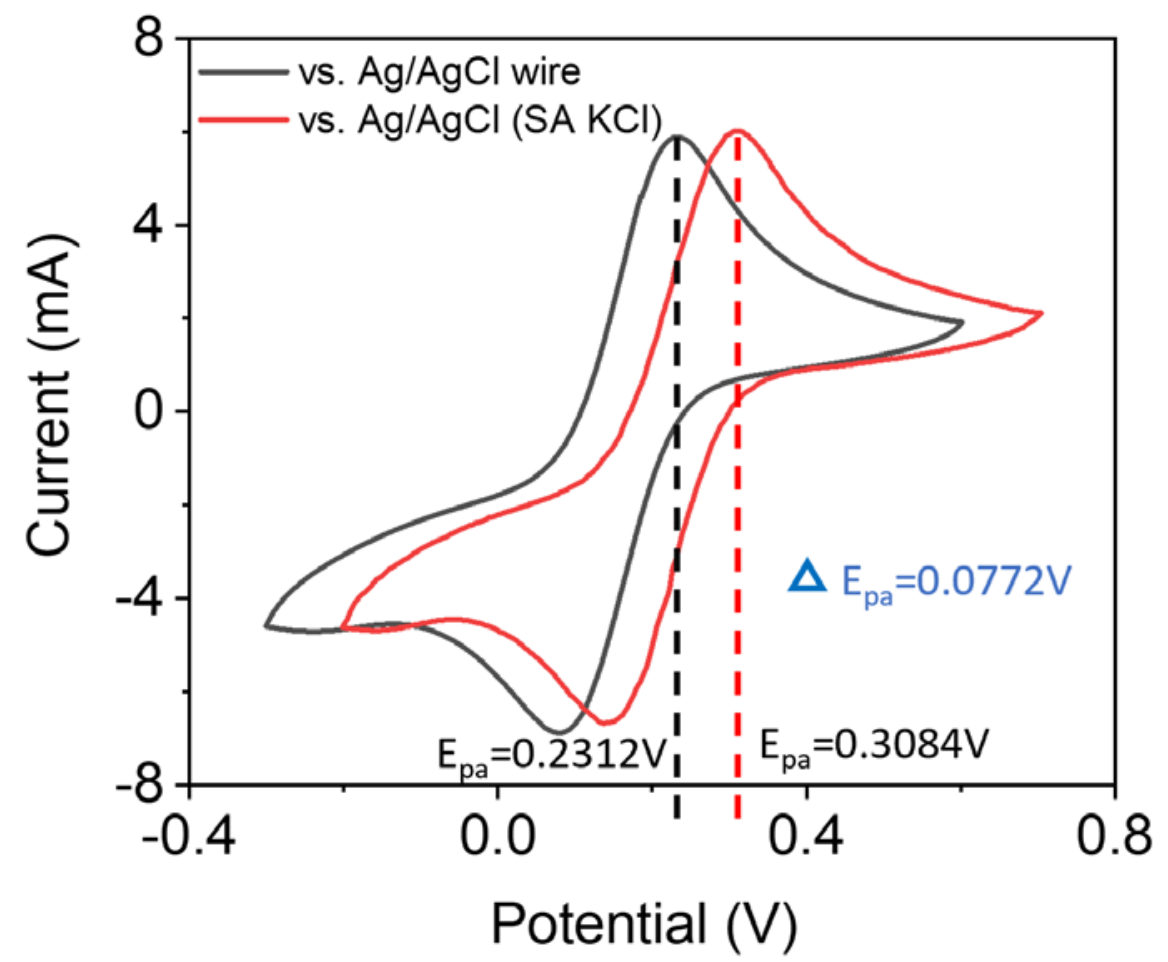

Figure S2. Cyclic voltammetry scans $(50 \mathrm{mV} / \mathrm{s})$ for Pt sheet electrode in $\mathrm{K}_{3}\left[\mathrm{Fe}(\mathrm{CN})_{6}\right](5 \mathrm{mM})$ with a $\mathrm{Ag} / \mathrm{AgCl}$ wire and a $\mathrm{Ag} / \mathrm{AgCl}$ (saturated $\mathrm{KCl}$ ) as the reference electrode respectively in the presence of $0.1 \mathrm{M} \mathrm{KCl}$. Temp: $25^{\circ} \mathrm{C}$. 

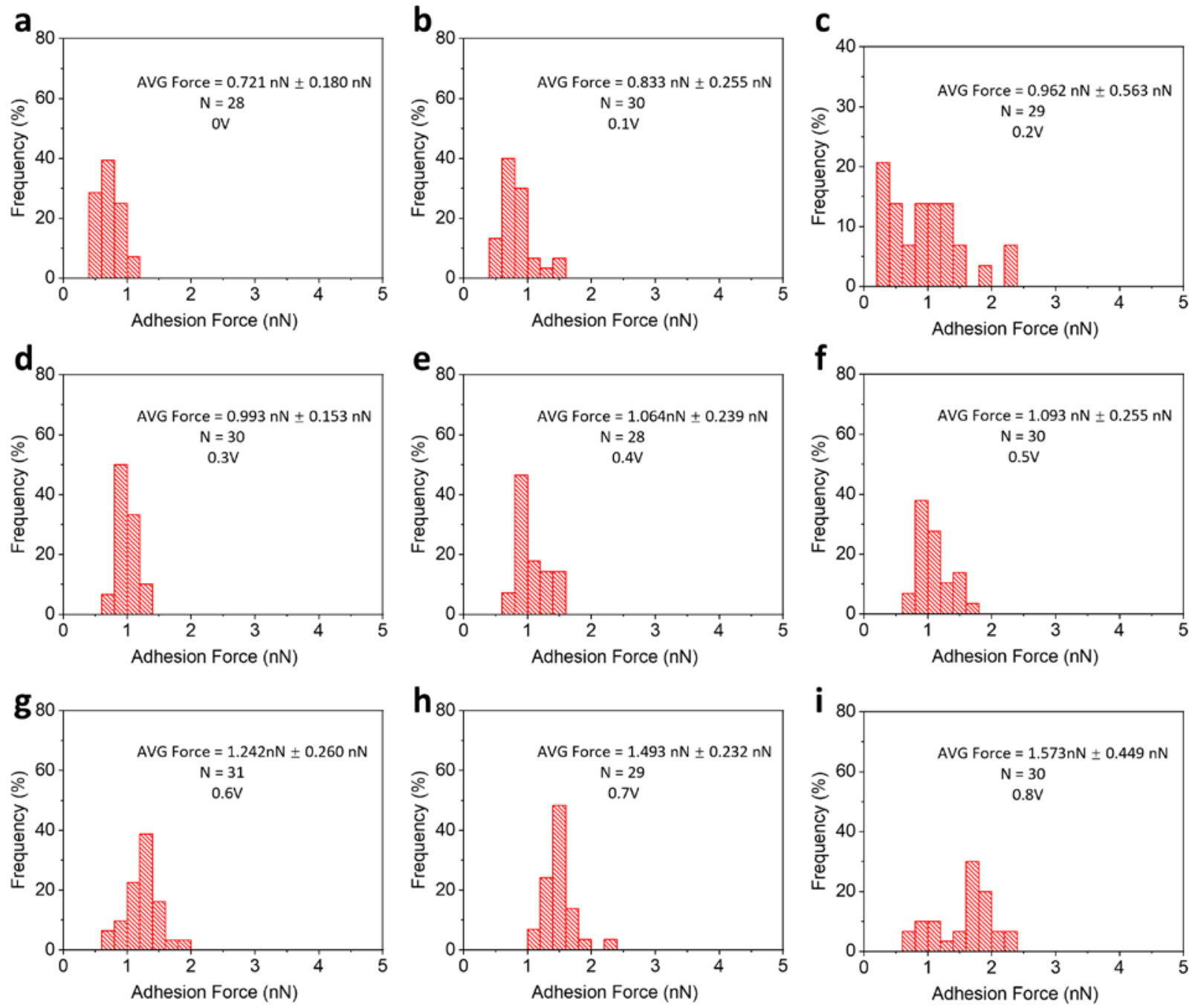

Figure S3. Histogram of the maximum adhesion force $\left(\mathrm{F}_{\mathrm{Ad}}\right)$ between a single $\mathrm{S}$. oneidensis MR-1 and a gold film electrode (WE) in PBS solution under aerobic conditions holding different electrode potentials. (a) $0 \mathrm{~V}$, (b) $0.1 \mathrm{~V}$, (c) $0.2 \mathrm{~V}$, (d) $0.3 \mathrm{~V}$, (e) $0.4 \mathrm{~V}$, (f) $0.5 \mathrm{~V}$, (g) $0.6 \mathrm{~V}$, (h) $0.7 \mathrm{~V}$, (i) $0.8 \mathrm{~V}$ vs. $\mathrm{Ag} / \mathrm{AgCl}$ (saturated $\mathrm{KCl}$ ). The inset shows the histogram average $\left(\mathrm{F}_{\mathrm{Ad}}\right)$, standard deviation, and number of measurements (N). Temp. $25^{\circ} \mathrm{C}$. 


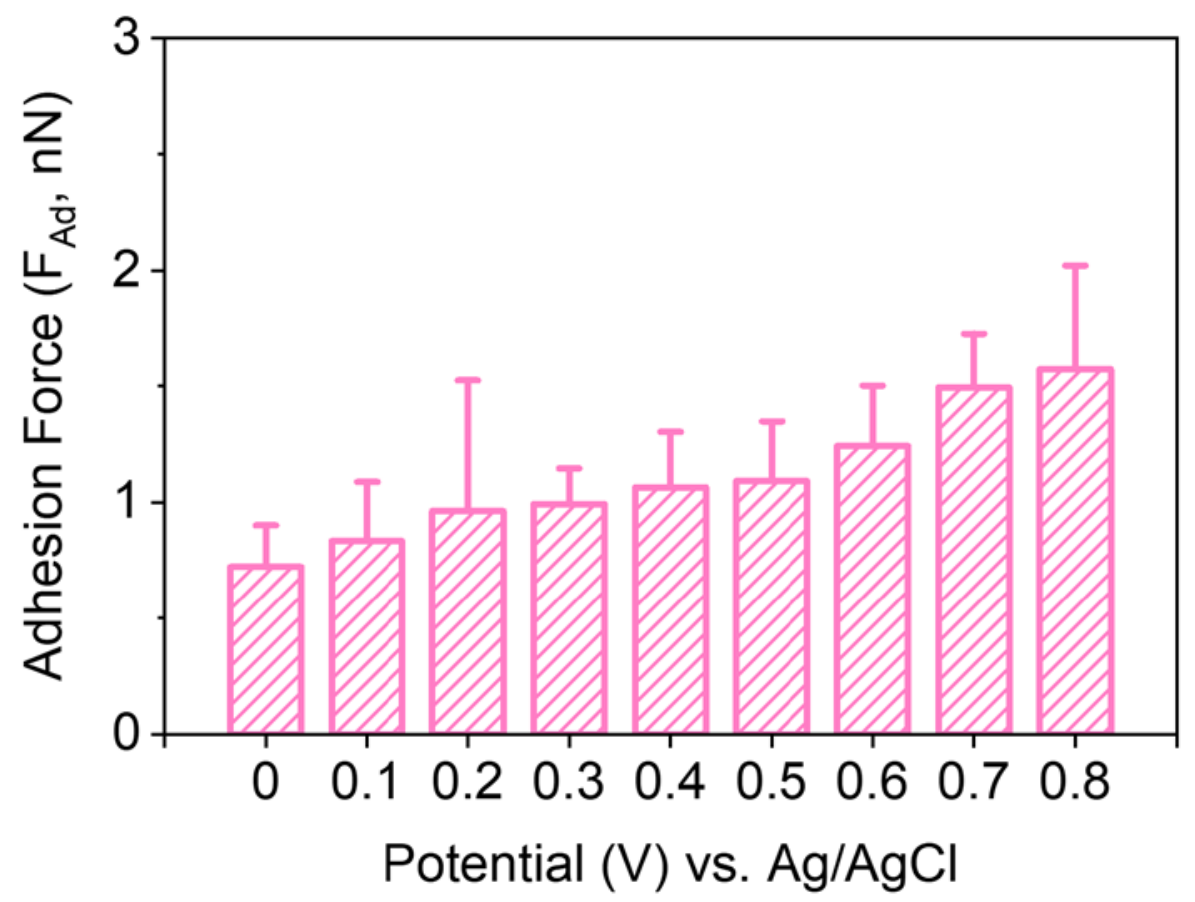

Figure S4. Maximum adhesion forces ( $\mathrm{F}_{\mathrm{Ad}}$ ) between a single $\mathrm{S}$. oneidensis MR-1 and a gold film electrode (WE) in PBS solution under aerobic conditions as a function of electrode potential vs. Ag/AgCl (saturated KCl). Temp. $25^{\circ} \mathrm{C}$. 


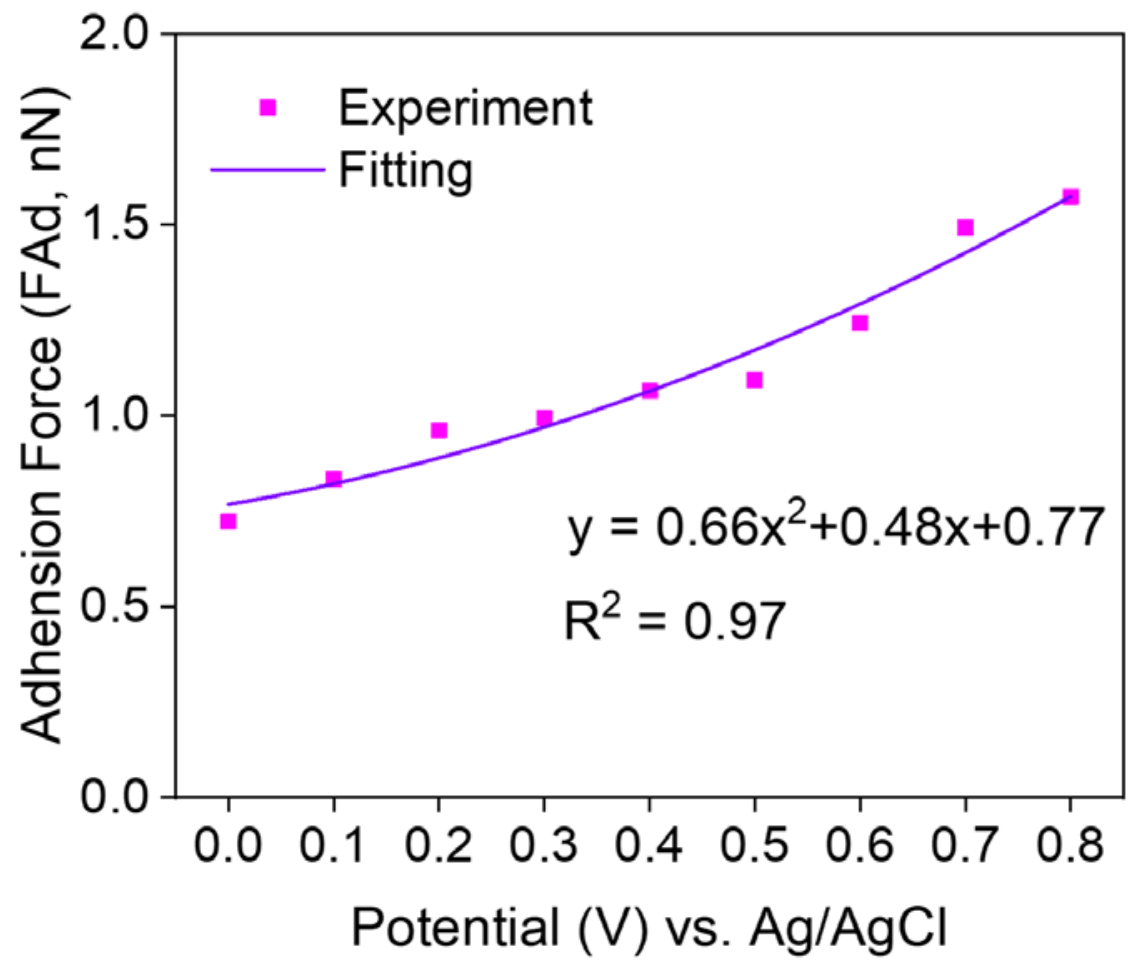

Figure S5. Fitting of the FAd data as a function of the potential with electrostatic force expression in PBS solution under aerobic conditions. 

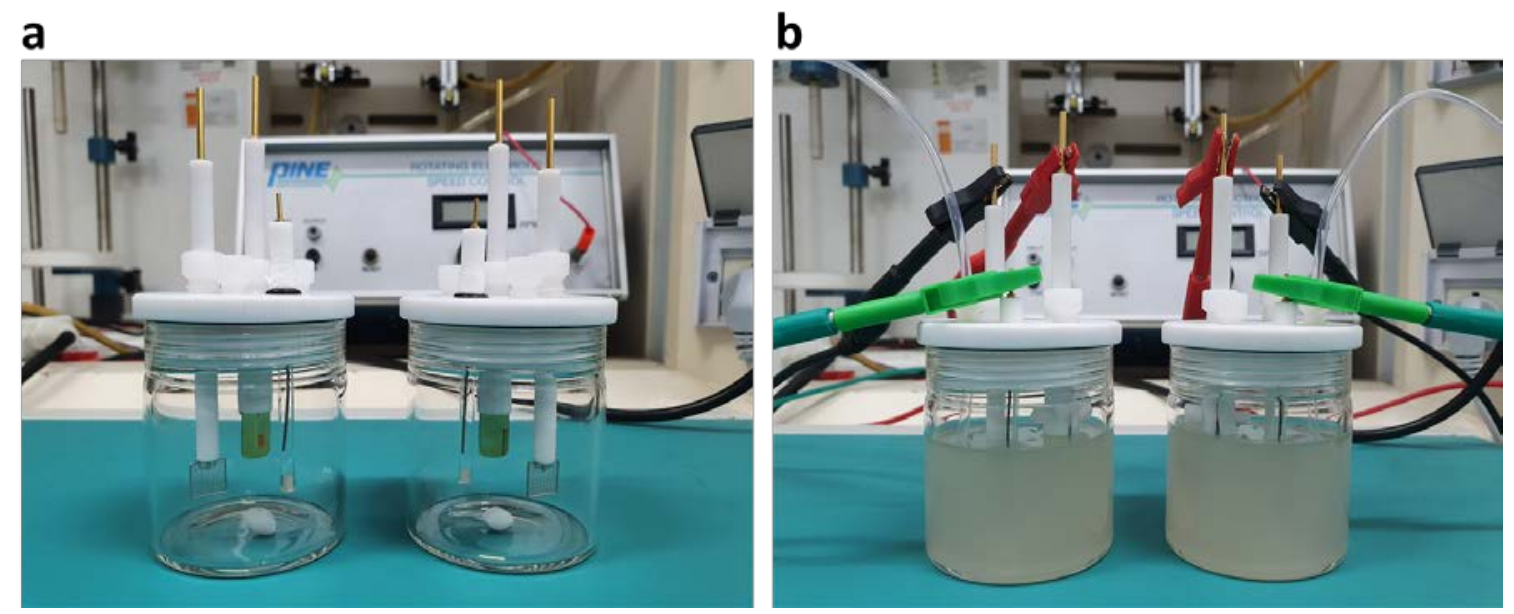

Figure S6. Images of the three-electrode reactors used to perform the biofilm formation experiments. 


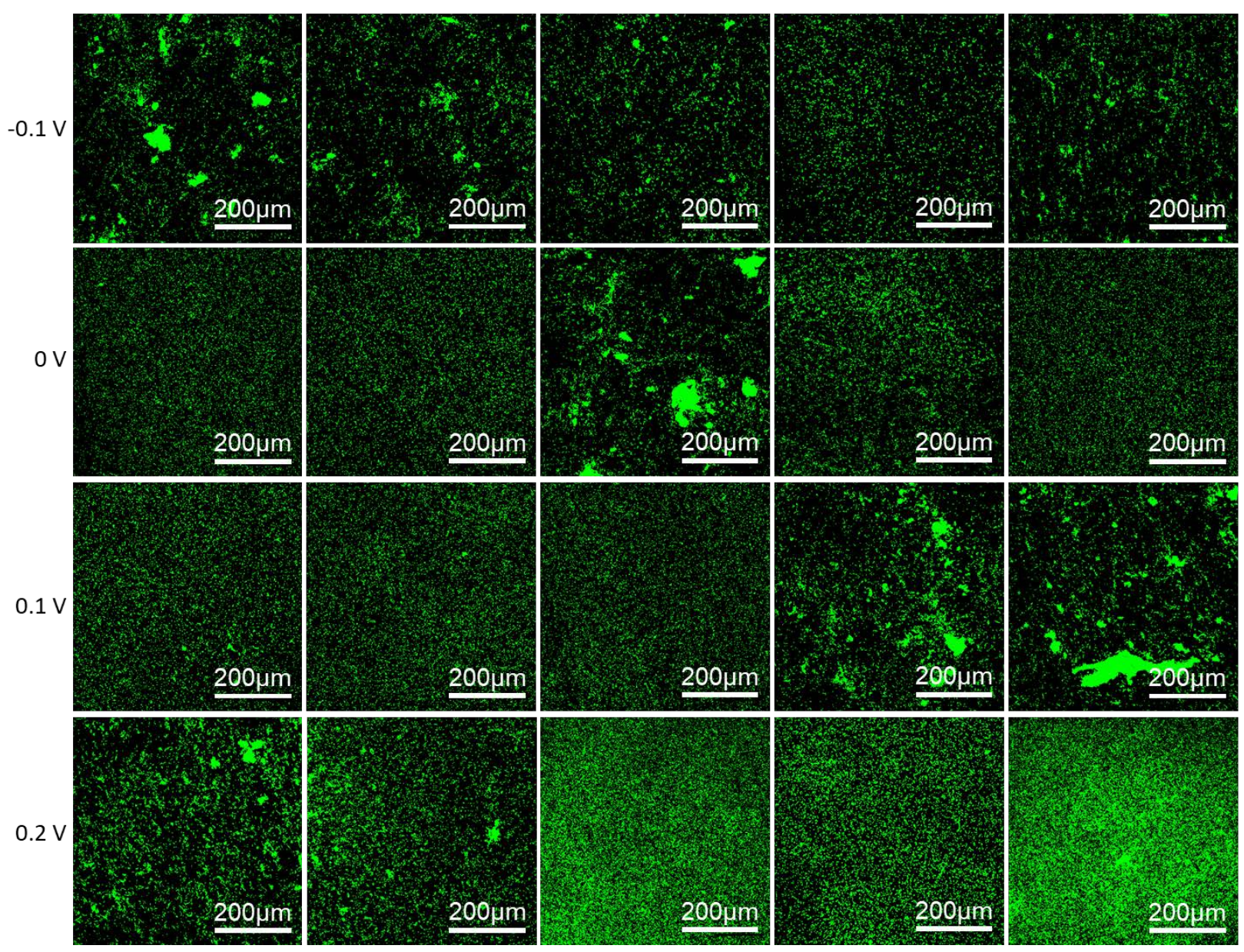

Figure S7. Microscope fluorescence images of S. oneidensis MR-1 biofilm formed on a gold film electrode (WE) under different electrode potential (vs. Ag/AgCl). Biofilm formation was conducted in a three-electrode reactor filled with M9 and $18 \mathrm{mM}$ sodium lactate (M9+SL), under anaerobic conditions with $200 \mathrm{rpm}$ magnetic stirring for $24 \mathrm{~h}$ at $25^{\circ} \mathrm{C}$. For every sample, five 600 $\times 600 \mu \mathrm{m}^{2}$ scanning areas were selected randomly. 


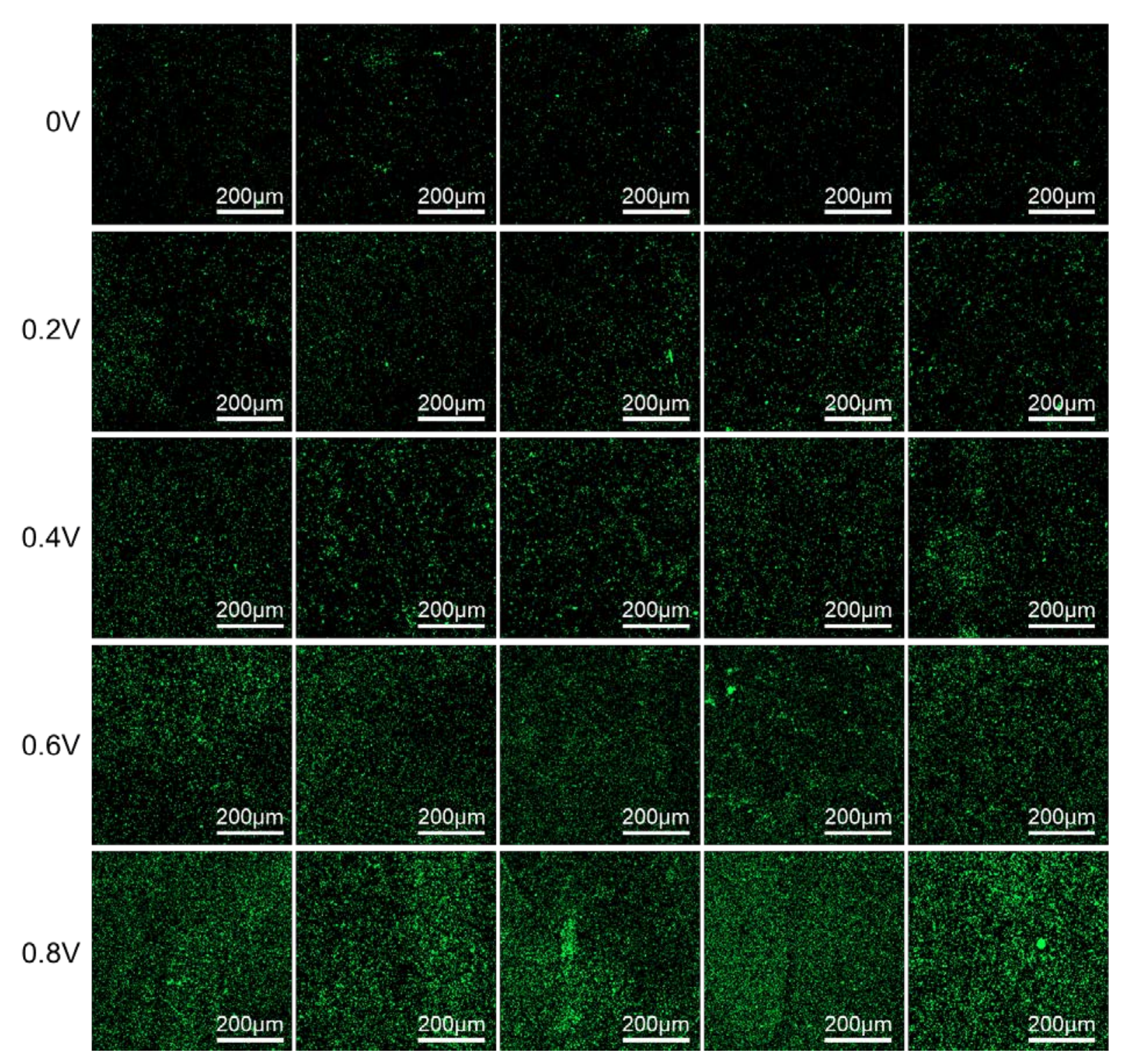

Figure S8. Microscope fluorescence images of S. oneidensis MR-1 biofilm formed on a gold film electrode (WE) under different electrode potential (vs. Ag/AgCl). Biofilm formation was conducted in a three-electrode reactor filled with M9 and 18 mM sodium lactate (M9+SL), under aerobic conditions with $200 \mathrm{rpm}$ magnetic stirring for $24 \mathrm{~h}$ at $25^{\circ} \mathrm{C}$. For every sample, five $600 \times$ $600 \mu \mathrm{m}^{2}$ scanning areas were selected randomly. 


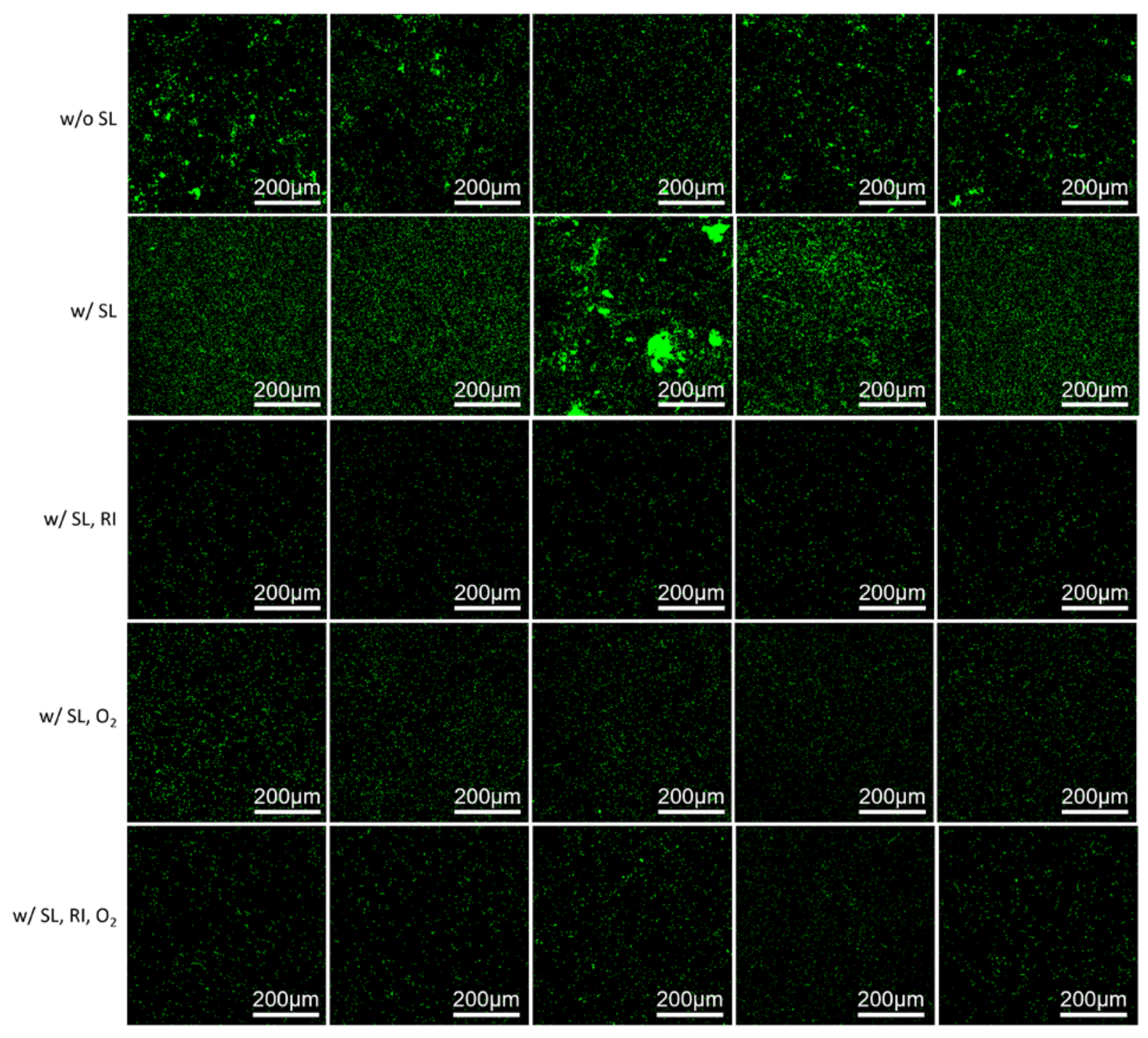

Figure S9. Microscope fluorescence images of $S$. oneidensis MR-1 biofilm formed on a gold electrode surface in M9 under different solution chemical conditions. Biofilm formation was conducted in a three-electrode reactor, holding WE at a potential of $0 \mathrm{~V}$ vs. $\mathrm{Ag} / \mathrm{AgCl}$ (saturated $\mathrm{KCl}$ ) with $200 \mathrm{rpm}$ magnetic stirring for $24 \mathrm{~h}$ at $25^{\circ} \mathrm{C}$. For every sample, five $600 \times 600 \mu \mathrm{m}^{2}$ scanning areas were selected randomly. 

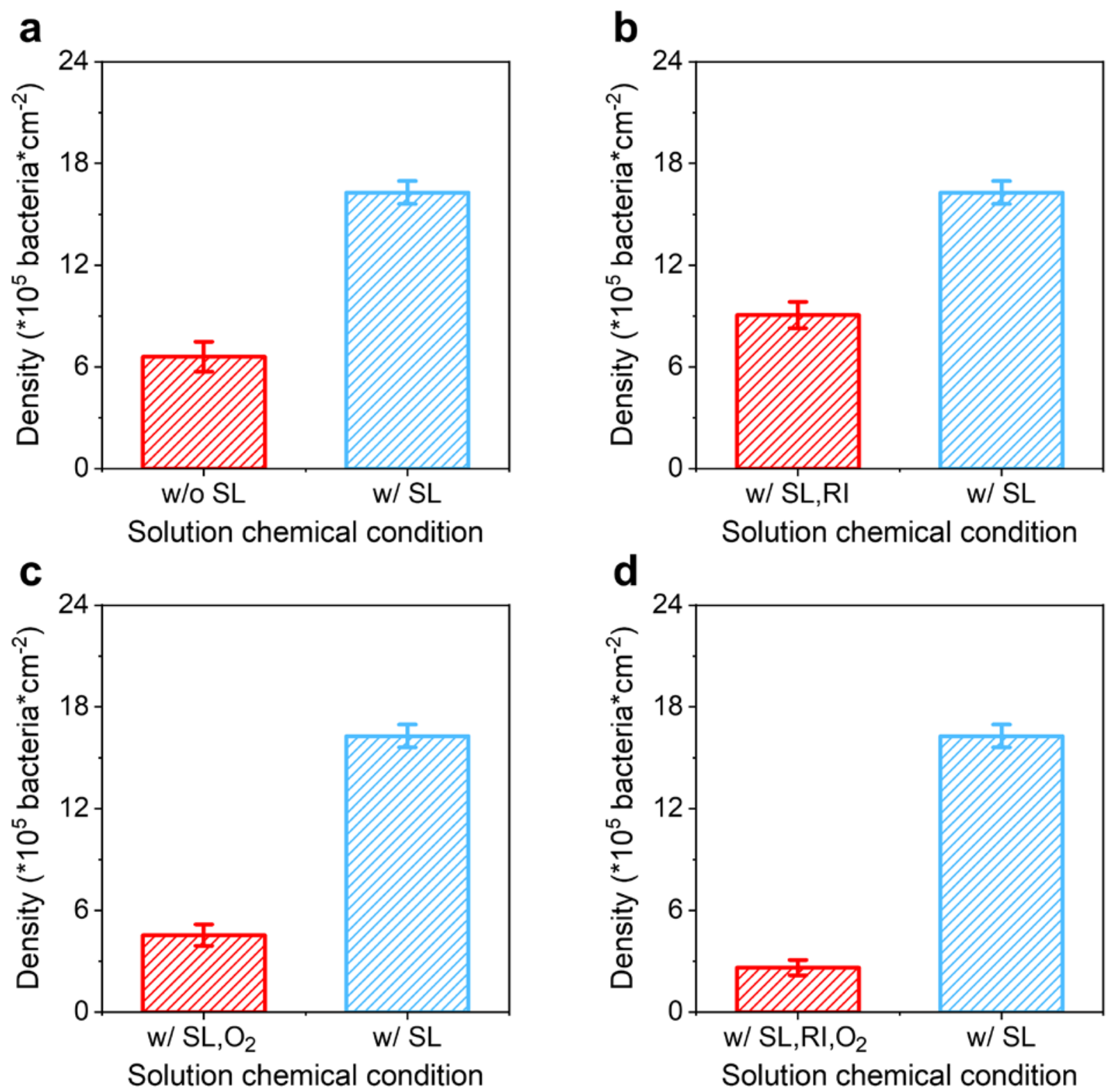

Figure S10. Bacteria density of the biofilm formed on a gold electrode under different solution chemical conditions. Biofilm formation was conducted in a three-electrode reactor filled with M9, holding $\mathrm{WE}$ at a potential of $\mathrm{OV}$ vs. $\mathrm{Ag} / \mathrm{AgCl}$ (saturated $\mathrm{KCl}$ ) with $200 \mathrm{rpm}$ magnetic stirring for $24 \mathrm{~h}$ at $25^{\circ} \mathrm{C}$. 


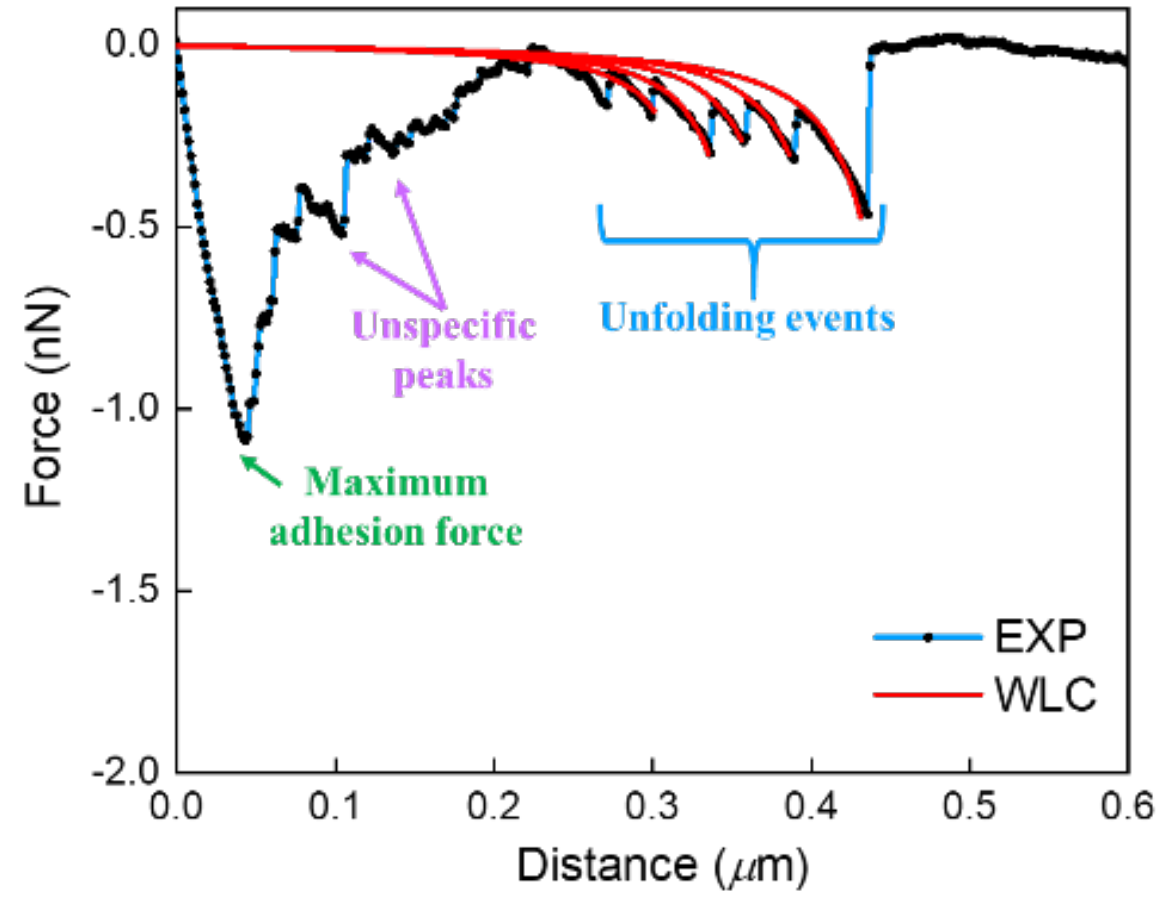

Figure S11. Fitting of the force-distance curve using the worm-like chain (WLC) model 


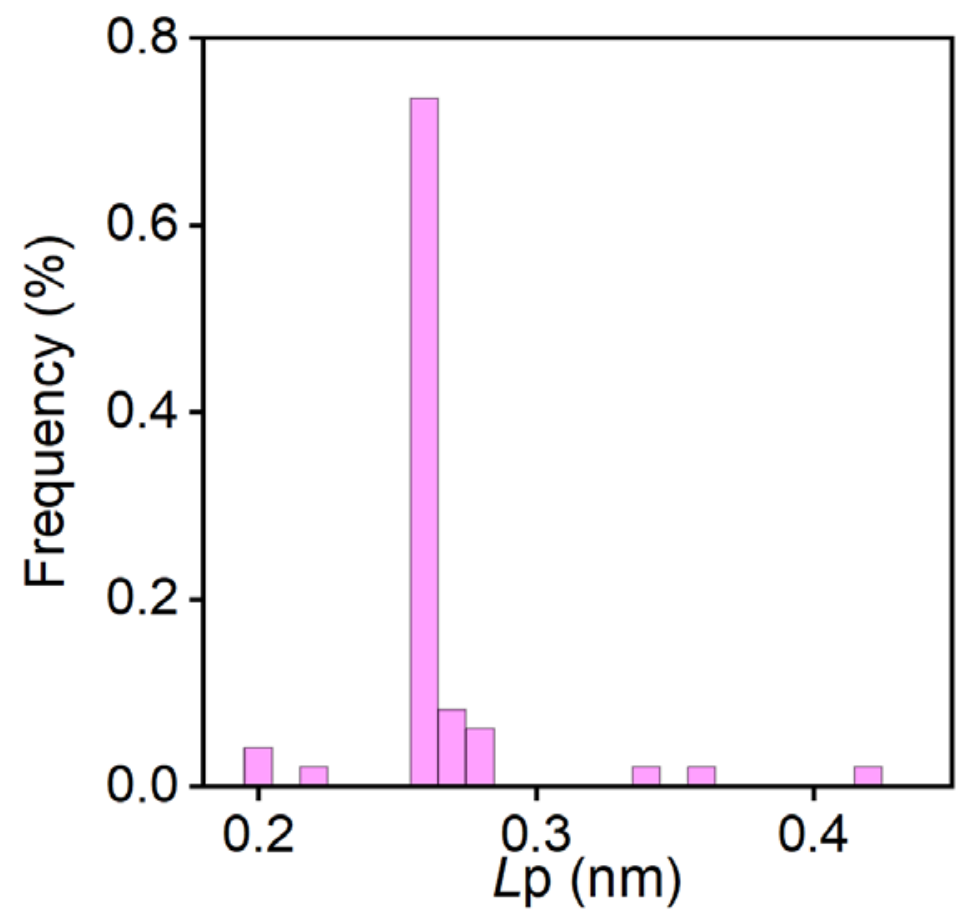

Figure S12. Distribution of the persistent length $L_{p}$ calculated from fitting the force-distance curves with a worm-like chain (WLC) model. 


\section{REFERENCES}

(1) Wuolo-Journey, K.; BinAhmed, S.; Linna, E.; Romero-Vargas Castrillón, S. Do graphene oxide nanostructured coatings mitigate bacterial adhesion? Environmental Science: Nano 2019, 6, 2863-2875.

(2) Xue, J.; Binahmed, S.; Wang, Z.; Karp, N.; Stottrup, B.; Castrillón, S. Bacterial Adhesion to Graphene Oxide (GO)-Functionalized Interfaces Is Determined by Hydrophobicity and GO Sheet Spatial Orientation. Environmental Science \& Technology Letters 2018, 5, 14-19.

(3) BinAhmed, S.; Hasane, A.; Wang, Z.; Mansurov, A.; Romero-Vargas Castrillón, S. Bacterial Adhesion to Ultrafiltration Membranes: Role of Hydrophilicity, Natural Organic Matter, and Cell-Surface Macromolecules. Environmental Science \& Technology 2018, 52, 162-172. 